\title{
CARCINOID HEART DISEASE
}

\author{
BY \\ JOHN COSH, J. E. CATES, AND D. W. PUGH \\ From the Department of Medicine, University of Bristol, and the Royal United Hospital, Bath
}

Received September 25, 1958

The association between heart lesions and metastasizing carcinoid tumours is now well known. The first description of this syndrome reported in England is that of Cassidy $(1930,1931)$ although the author did not appreciate the nature of the liver metastases and their connection with the pulmonary valve stenosis. Scholte (1931) in his description of a case of metastasizing carcinoid tumour with heart valve lesions considered the possibility of an association between the two. Similar observations were made by Biorck et al. (1952), by Isler and Hedinger (1953), and by Rosenbaum et al. (1953). It was Waldenstrom and Ljungberg in 1953 who suggested that secretion of 5 hydroxy-tryptamine ( $5 \mathrm{H}$-T; serotonin; enteramine) by metastases in the liver might cause the lesions in the right side of the heart. Detailed studies by Thorson et al. (1954) and by Waldenstrom and Ljungberg (1955) established that in patients with the carcinoid syndrome there is an increase in the circulating $5 \mathrm{H}-\mathrm{T}$ which is derived from the tumour deposits in the liver, and that this substance is present in higher concentrations in the right heart blood than in the systemic circulation. $5 \mathrm{H}-\mathrm{T}$ is known to be largely inactivated in its passage through the lungs (Sjoerdsma et al., 1956; Goble et al., 1955, 1956). An inactive breakdown product, 5 hydroxy-indole acetic acid (5 H.I.A.A.) is formed and passes into the general circulation and is excreted in the urine: it can be measured by the methods of Udenfriend et al. (1955), and of Hanson and Serin (1955) and high urinary levels confirm the diagnosis of metastasizing carcinoid tumour.

Although recent reviews have been published by Macdonald and Robbins (1957), and Thorson (1958), detailed accounts of the fully developed syndrome are uncommon. In this paper three patients with carcinoid heart disease are described together with the findings post mortem.

\section{CASE 1}

A widow, aged 64, developed a dusky red face and painless watery diarrhœa in the summer of 1954 , and in the August she began to have headache, anorexia, and vomiting for which she was admitted to hospital. She was found to have bilateral hydronephrosis with hypertension (B.P. 220/115): the urine contained a little protein and scanty red and white cells, and the blood urea was $120 \mathrm{mg}$. per $100 \mathrm{ml}$. Her symptoms improved with rest in bed. She remained under her own doctor for the next two years; during this time the flushing of her face increased and the diarrhœa became worse; she lost two stones in weight and, in December, 1955, she began to have redness and swelling of her hands and feet and peeling of the skin of her extremities and abdomen; there was periodic itching and redness of the skin over these sites. She became short of breath on exertion and developed severe odema; and she was readmitted to hospital in February, 1956.

The family history revealed three cases of malignant disease: her mother had died of uterine carcinoma, a sister of carcinoma of the stomach, and a brother of carcinoma of the prostate.

On examination her appearance was spectacular for her face was purple and cyanotic, suggesting polycythæmia, and there were many fine telangiectases; her hands and feet were dark red, and the rest of her skin was less deeply coloured. In addition there were frequent bright patches of red flushings over the face 
and chest lasting for a minute or two at a time. She was unaware of the flushes, which were not accompanied by any change in the pulse rate or blood pressure. The jugular veins were filled to the level of the angle of the jaw when she was sitting, and there was gross pitting odema of the legs, lumbar region, and lower abdominal wall. The retinal veins were engorged. The pulse was regular and the blood pressure 180/100. The apex beat was in the sixth interspace in the anterior axillary line. There was a harsh systolic murmur with thrill at the tricuspid area and a short early diastolic murmur at the pulmonary area. There were expiratory rhonchi over the lungs and the bases were free from râles. The liver was much enlarged with the lower edge in the right iliac fossa and it was hard and nodular. Visible peristalsis and borborygmi were noted. Rectal examination was normal.

Chest X-ray showed considerable increase in the cardiac diameter, involving the right atrium and both ventricles; there was a small left-sided pleural effusion. The electrocardiogram showed sinus rhythm and low voltage complexes without evidence of right ventricular hypertrophy.

The diagnosis made was of malignant carcinoid with hepatic deposits and consequent lesions of the tricuspid and pulmonary valves, and congestive heart failure.

Investigations. Estimations of the 24-hourly urinary output of 5 hydroxy-indole acetic acid by the method of Hanson and Serin (1955) were: 247, 200, 350, 164, and $234 \mathrm{mg}$. (normal under $10 \mathrm{mg}$. $/ 24$ hours). Hæmoglobin 12.6 g. per $100 \mathrm{ml}$. Platelets $276,000 / \mathrm{cu}$. mm. Non-protein-nitrogen $34 \mathrm{mg}$. and plasma bilirubin $0.2 \mathrm{mg}$., each per $100 \mathrm{ml}$. Alkaline phosphatase $12.7 \mathrm{~K}$.A. units. Serum proteins $5 \cdot 2 \mathrm{~g}$. per $100 \mathrm{ml}$. (albumen $2 \cdot 7$, globulin $2 \cdot 5$ ). The stools contained occult blood.

Progress. With rest in bed and mersalyl she lost her signs of congestive failure and on codeine her diarrhoa lessened, and she went home. The odema soon returned and in September, 1956, she was readmitted; she was now deeply jaundiced, emaciated, drowsy, and confused. Her facial appearance and the flushings were unchanged and diarrhœa persisted. The liver was no bigger, though the nodules were more easily felt. At first she improved on bed rest and mersalyl, but the oedema later increased. The blood non-protein nitrogen rose to $200 \mathrm{mg}$. per $100 \mathrm{ml}$. She became drowsy and weak and died in October, 1956.

Necropsy (Professor T. F. Hewer). The abdominal cavity contained $1500 \mathrm{ml}$. of deeply bile-stained fluid. There were no adhesions. In the ileum, $55 \mathrm{~cm}$. above the ileo-cæcal valve the gut was acutely kinked at the site of a rounded tumour about $1 \mathrm{~cm}$. in diameter, arising in its wall. The tumour projected into the lumen of the gut, was covered with intact mucosa, and invaded the serous coat. There was a Meckel's diverticulum, $5 \mathrm{~cm}$. below the tumour, with a small nodule in its wall. A group of enlarged lymph nodes lay in the mesentery. The liver $(2600 \mathrm{~g}$.) was acutely congested and jaundiced, and contained many tumour metastases, mainly in the right lobe, the biggest measuring $8 \times 10 \times 19 \mathrm{~cm}$. They were pale and of uniform texture on section, containing occasional areas of central necrosis. The spleen $(165 \mathrm{~g}$. $)$ showed acute congestion only. The kidneys were hydronephrotic without visible cause of obstruction to the ureters. In the pleural cavities there were small effusions. The lungs showed areas of collapse at their bases with patches of broncho-pneumonia. There were a number of small pale metastatic deposits beneath the pleural surfaces.

The heart weighed $240 \mathrm{~g}$. The epicardium and pericardium were normal. The left atrium and ventricle, and the mitral and aortic valves were normal. The right atrium was greatly dilated and had a patchy white deposit upon its endocardial surface. The tricuspid valve was $11 \mathrm{~cm}$. in circumference, and its cusps were thickened and opaque and narrowed from above downwards. White deposits had converted two of the larger chordæ tendineæ into white conical pillars, the base of the cone being attached to the cusp margin, and white material extending from the apex on to the papillary muscle in each case. The right ventricle was greatly dilated and hypertrophied and its endocardium was normal. The pulmonary valve (Fig. 1A) had a circumference of $6.5 \mathrm{~cm}$. (normal 8.5 to $9 \mathrm{~cm}$.; Ross, 1948). Its cusps were thickened and adherent at their commissures, and the free margins were rolled inwards towards the sinuses. The appearance suggested the presence of both stenosis and incompetence. The main pulmonary artery was dilated, but no deposit of any kind was seen in its wall or in its main branches.

Histology. The ileal tumour was a typical carcinoid arising in the submucosa and invading the muscle and subserous coats. It was composed of argentaffin cells lying in groups or islets surrounded by an abundant fibrous stroma. The nuclei of the tumour cells varied greatly in size and stained deeply, giving a malignant appearance. The nodule in the Meckel's diverticulum was another carcinoid, but did not appear malignant. Metastases in the mesenteric lymph nodes and liver were composed of argentaffin cells similar to those in the ileal tumour. The deposit on the wall of the right atrium was composed of layers of collagen loosely packed, applied to the surface of the endocardium, the elastic lamina of which was intact. No fibrin or hæmosiderin was present. The tricuspid valve cusps were thickened by the deposit upon their atrial surfaces of acellular collagen. The affected chordæ could be identified as small round structures with an intact elastic lamina embedded in a mass of collagen. The pulmonary valve (Fig. 2A) cusps were thickened by deposits applied both to their proximal and distal surfaces. Some fine blood vessels could be seen beneath the endocardium of the cusps and also between the cusps and the collagen deposit. In the lungs there were small tumour metastases, mostly just beneath the pleura, and some small clumps of tumour cells lay within lymphatics. In a few small arteries the lumina were narrowed by hyaline subendothelial thickening. 
Summary. This woman, aged 66, had diarrhœa for two years, a dusky facial colour, and flushings. Later she lost weight and developed congestive heart failure with evidence of pulmonary and tricuspid valve lesions. The liver was enlarged and nodular. The clinical diagnosis of metastasizing carcinoid with heart disease was supported by high urinary output of 5-H.I.A.A. Extensive endocardial changes were found post mortem.

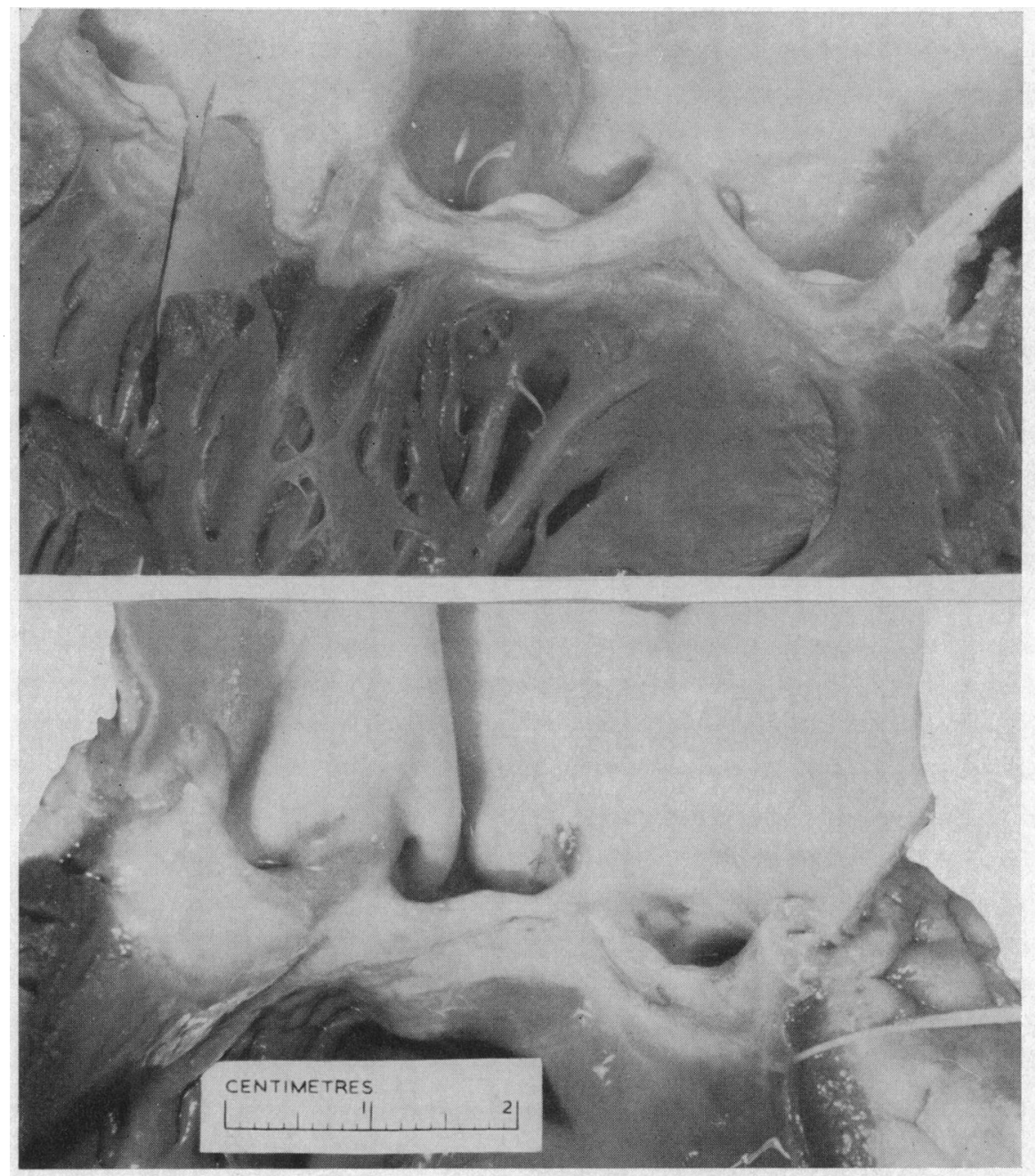

FIG. 1.-Pulmonary Valve. (A) The cusps are thickened and their margins are rolled in to the sinuses. Case 1. (B) A thick white deposit lies over the cusps, binding them together at the commissures and spreading down on to the ventricular muscle. Case 2.

\section{CASE 2}

A housewife, aged 64, was first seen in December 1955 with a month's history of progressive odema of her legs, thighs, and lower abdomen. She had cyanosis of the face and lips. The jugular veins were filled to the level of the angle of the jaw when she was sitting, and the liver margin was felt $10 \mathrm{~cm}$. below the costal margin; there was no pulsation in the neck veins or in the liver. She was able to lie flat without distress, and the lung bases were free from râles. The pulse was regular and the blood pressure 170/100. The apex beat was in the sixth interspace in the anterior axillary line. A systolic murmur was heard at the pulmonary area and at the apex. Fluoroscopy showed generalized cardiac enlargement and cardiac movements of small amplitude. The electrocardiogram showed sinus rhythm, right axis shift, and some 


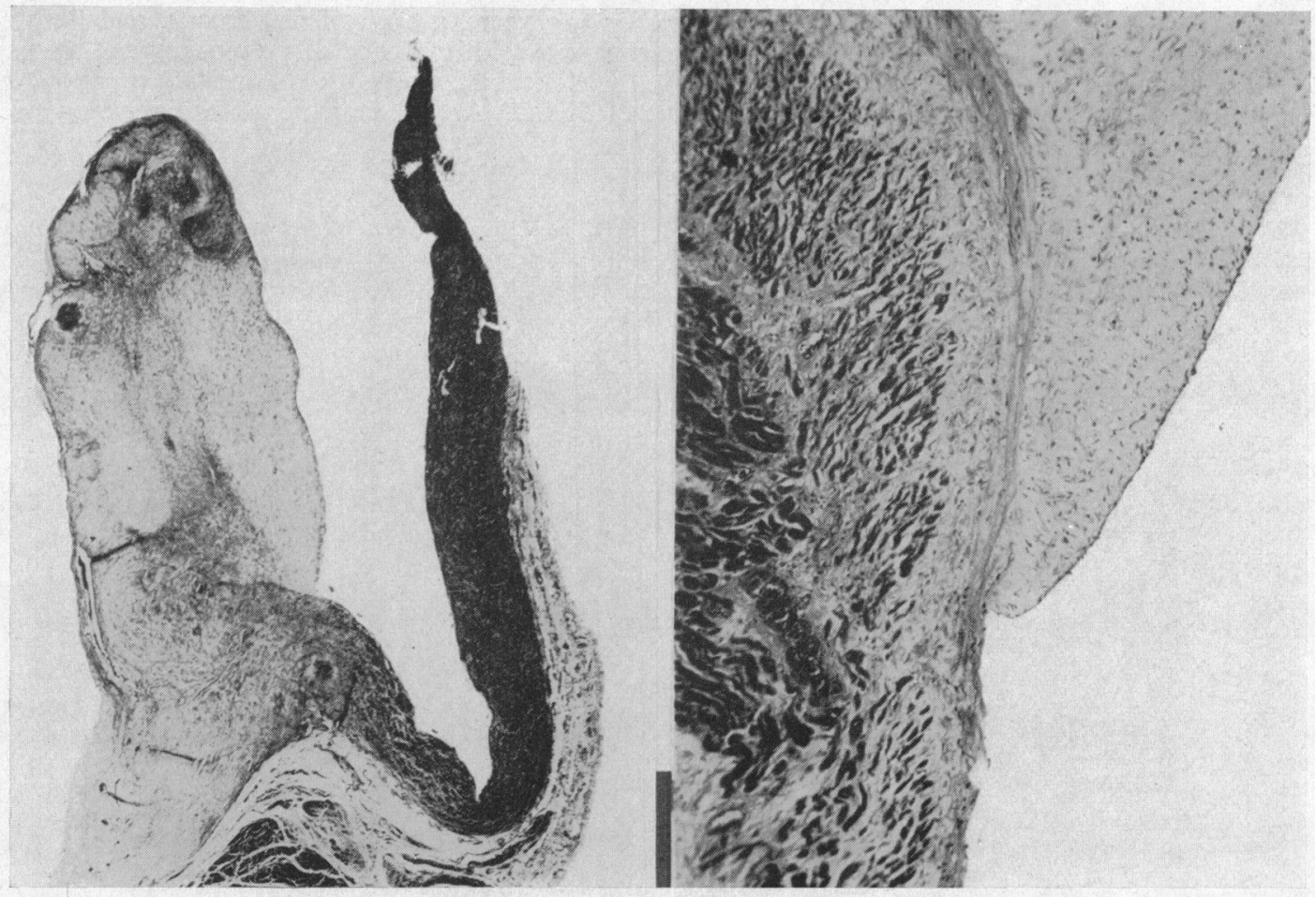

Fig. 2.-Histology of the Deposit. (A) Section through cusp of the pulmonary valve, on left, and wall of the pulmonary artery, on right. The margin of the cusp is rolled over to the right, and bound down by deposit, which continues to the bottom of the sinus, but not on to the artery wall. $\times 20$. Case 1 . (B) Section through edge of deposit lying on right atrial wall. The internal elastic lamina is unbroken, and clearly shows the boundary between endocardium and deposit. Nuclei of fibroblasts are seen in the deposit. $\times 100$. Case 3 .

evidence of right ventricular hypertrophy. A diagnosis was made of tricuspid stenosis, presumably of rheumatic origin, with congestive failure, although she had no history of acute rheumatism.

Progress. Her congestive failure responded to rest in bed, digitalis, and mersalyl. However, in April, 1956, her symptoms returned and she now developed diarrhœa with bowel actions 3 or 4 times daily. On admission to hospital in May, 1956, she had a dusky cyanotic facial colour, with fine telangiectases on the cheeks. No flushings were seen. As well as venous congestion and odema she had now developed ascites. Her cardiac signs were unchanged though some observers felt a systolic thrill at the pulmonary area, and there was a short mid-diastolic sound heard in the tricuspid area. After improving at first, she gradually deteriorated, becoming drowsy and fretful and losing weight. For a week she was found to have extensor plantar responses, without other neurological signs; the responses then became flexor again. The liver enlarged further and diarrhœa continued; per rectum a firm diffuse induration was felt throughout the pelvis but there was no definite mass. She died in July, 1956. The final clinical diagnosis was of an intra-abdominal malignant tumour of undetermined site, with secondary metastases in the liver, associated with tricuspid stenosis and congestive failure.

Investigations. Hæmoglobin 15.4 g. per $100 \mathrm{ml}$. W.B.C. 9400 per cu. $\mathrm{mm}$. Blood urea, $70 \mathrm{mg}$. per $100 \mathrm{ml}$. Stools: no blood present, no pathogenic bacteria. Serum proteins, $7 \cdot 2 \mathrm{~g}$. per $100 \mathrm{ml}$. (albumen $3 \cdot 9$, globulin 3.3). Blood WR, negative.

Necropsy (Professor T. F. Hewer). The abdominal cavity contained a few hundred ml. of strawcoloured fluid, and was almost obliterated in its lower part by dense fibrous adhesions in which the small intestine and pelvic organs were bound together. The inferior vena cava was formed at the level of the renal veins by the junction there of the two common iliac veins. There was no obstruction to the lumina of the veins nor was there venous thrombosis. In the upper ileum a tumour $1 \mathrm{~cm}$. in diameter was found, lying at a point of acute angulation in the intestine; the tumour lay beneath the intact mucosa and invaded the muscle coat of the ileum. There was a group of enlarged lymph nodes nearby in the mesentery. The liver (1790 g.) had a roughened irregular surface from cardiac cirrhosis, and contained several large rounded 
deposits of tumour; their surface was pale and homogeneous on section. The kidneys showed bilateral acute pyelonephritis with inflamed and dilated pelves; both ureters were compressed by the pelvic fibrous tissue in which they lay. The brain $(1375 \mathrm{~g}$.) had a normal external appearance. On section, a small area of softening $4 \mathrm{~mm}$. in diameter was found in the corona radiata in the left hemisphere and there was a similar lesion in the pons. The pleural cavities each contained a litre of fluid. The lungs both showed compression and collapse of their lower lobes, but no metastatic deposits.

The heart weighed $325 \mathrm{~g}$; ; the epicardium and pericardium were normal. The left atrium and ventricle, and the mitral and aortic valves were normal. The right atrium was greatly dilated, and its endocardium was almost entirely coated with a pearly white layer $1-2 \mathrm{~mm}$. thick, giving its wall a leathery consistency. This coat extended on to the tricuspid valve (Fig. 3A) which was grossly thickened and deformed. Its

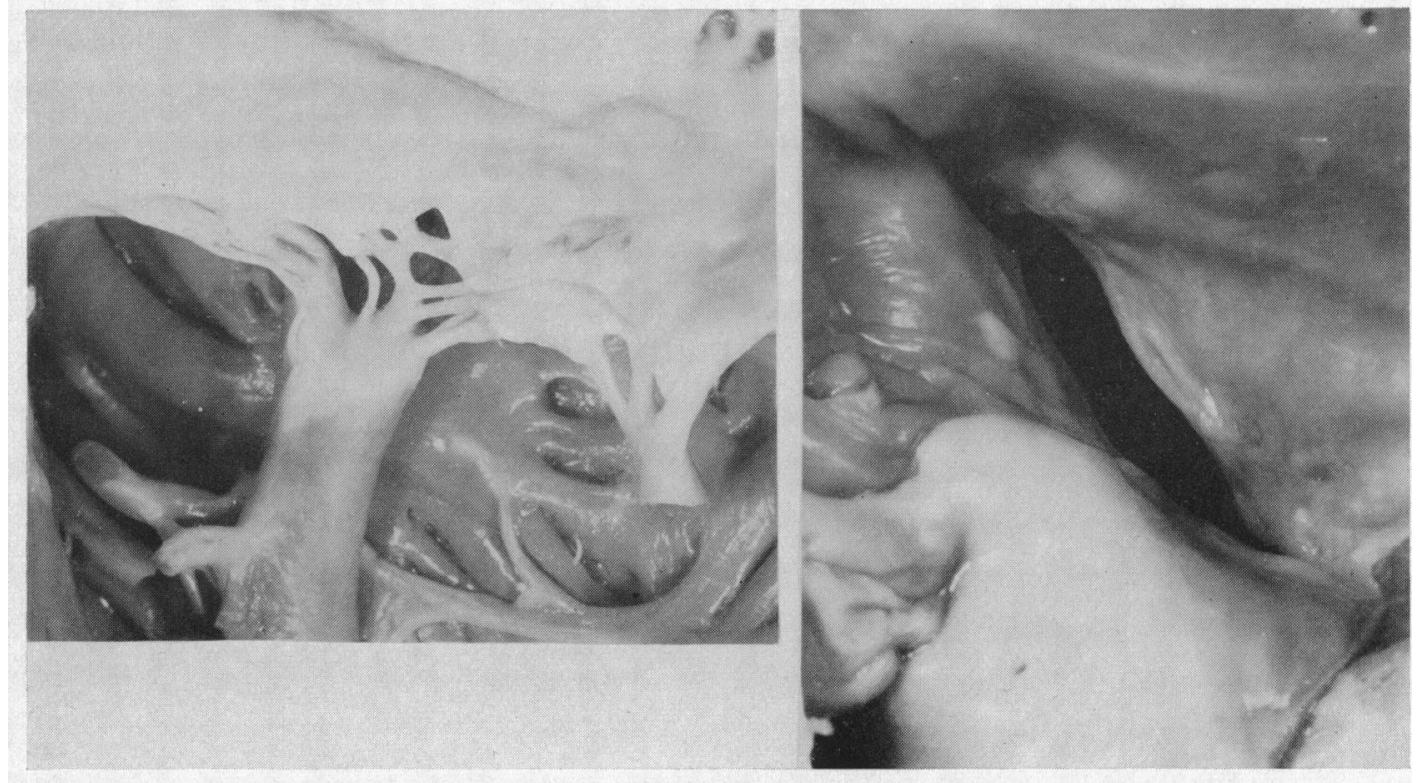

Fig. 3.-Tricuspid Valve. (A) Gross thickening of the cusps. The chordæ are encased in white deposit which encroaches on to the papillary muscle on the left; that on the right has been cut. Case 2. (B) Atrial aspect of the stenosed and incompetent valve. A thick plaque of deposit is seen in the foreground lying near the orifice. Case 3.

circumference was $8.5 \mathrm{~cm}$. (normal, 12-12.7 cm.; Ross, 1948), and its chordæ were short and thick, the deposit continuing along them on to the papillary muscles. It appeared that the valve must have been both stenosed and incompetent. The right ventricle was dilated and hypertrophied, and its walls were free from deposits. The pulmonary valve (Fig. 1B) was stenosed, with a circumference of $5 \mathrm{~cm}$. Its cusps were adherent at their comissures and thickened, with their free margins rolled towards the sinuses.

Histology. The ileal tumour was a typical malignant carcinoid, its argentaffin cells lying in a thick scirrhous stroma, and invading the muscle coats of the intestine. The mesenteric glands and liver contained metastases of argentaffin cells of similar appearance. The peritoneal adhesions contained no tumour cells, but were composed entirely of fibrous tissue. In the right atrium the thickened endocardial areas were seen to consist of collagen applied in strands running parallel with the endocardial surface, without breaking or penetrating the internal elastic lamina, which clearly marked the separation between deposit and endocardium. Deposits on the tricuspid valve were mainly on the ventricular surfaces of the cusps, and were applied to its surface without invading it. A few histiocytes were seen in the deposit, containing grains of hæmosiderin. A frozen section of the right ventricular myocardium showed a fine fatty infiltration of all the muscle fibres; there was no fat in the endocardial deposits. Several sections of the lungs showed intimal thickining in the smaller branches of the pulmonary arteries.

Summary. This woman died, aged 64, after less than a year's illness. She had progressive œdema with an enlarged liver, dusky facial cyanosis, and evidence of tricuspid stenosis. The œdema at first responded to digitalis and mersalyl but recurred. Necropsy showed an ileal carcinoid tumour and hepatic metastases, with lesions of the right atrium and tricuspid and pulmonary valves. 


\section{CASE 3}

A man, while serving in the Royal Air Force in 1943 at the age of 21 years, began to notice transient flushing of the face, lasting not more than three minutes at a time, every few days. He also had attacks of dizziness without flushing, on one occasion followed by a brief loss of consciousness. His bowel actions were loose but they had always been so. In 1946 he was demobilized in physical category A1. The facial flushes became more obvious and by 1950 he noticed that a series of flushes would lead to odema of his eyelids and beneath his chin, followed some hours later by the passage of large amounts of urine. The attacks of dizziness continued, particularly on standing up from a lying position, when he would sometimes briefly lose consciousness. By this time his face was ruddier than before, and in cold weather his cheeks and lips were deeply cyanosed. This was attributed to polycythæmia. In 1956 he began to have dyspnoea on effort and attacks of tightness in the chest with wheezing and giddiness. Bowel action continued to be loose and frequent, up to six times daily. A metastasizing carcinoid tumour was suspected, and he was admitted to hospital for investigation.

On examination his face was plum coloured with a fine generalized telangiectasia (Fig. 4), and a similar cyanosis was seen on the upper arms and beneath the finger nails. Superimposed red flushes were not observed, nor were there periods of bronchospasm. He was well built and had lost no weight (weight $182 \mathrm{lb}$., height 70 inches). There was no œdema. The neck veins were filled to $5-7 \mathrm{~cm}$. above the clavicle

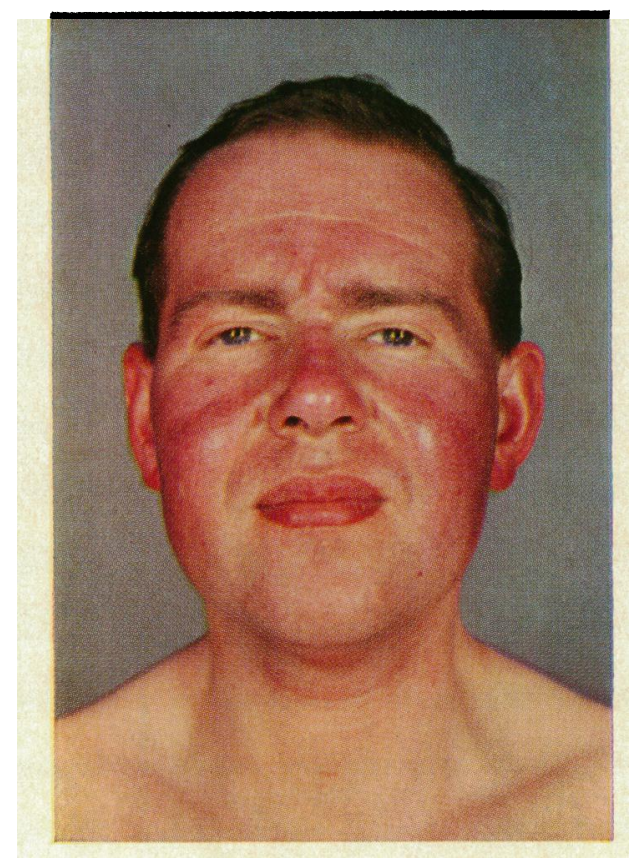

FIG. 4.-Colour photograph of Case 3, showing the deep red colour of his face and ears.

in the sitting position and there was a bounding expansile pulsation in the superficial and deep jugular veins immediately following ventricular systole. The pulse was regular and blood pressure 160/110. The cardiac apex was in the fifth interspace in the midclavicular line and the heart sounds were normal. There was a systolic murmur at the tricuspid area followed by a short mid-diastolic murmur. The lungs were clear. The liver was enlarged nearly to the umbilicus and was hard and smooth, with expansile pulsation in time with the neck veins.

Chest X-ray showed generalized cardiac enlargement with a cardiothoracic ratio of 55 per cent and particular involvement of the right atrium and ventricle. The electrocardiogram showed right axis shift with right ventricular hypertrophy.

Investigations. Urinary excretion of 5-hydroxy-indole acetic acid was much increased, being 116 and $114 \mathrm{mg}$. per 24 hours by Hanson and Serin's method. Hæmoglobin 17 g. per $100 \mathrm{ml}$; ; red cells $5 \cdot 7$ million per cu. mm.

At diagnostic laparotomy (Mr. T. Schofield, January, 1957) it was seen that the liver was grossly enlarged and contained tumour deposits; no primary tumour was found in the ileum and there were no peritoneal adhesions. Histological examination (Dr. R. L. Bishton) showed the liver deposits to be composed of argentaffin cells arranged in masses lying in a fibrous stroma. 
Progress. Dibenylene was given in doses of $100 \mathrm{mg}$. twice daily as an antagonist to $5 \mathrm{H}-\mathrm{T}$. Diarrhœa lessened but the facial appearance and the urinary output of 5-H.I.A.A. were unchanged. Later rauwolfia was given without effect. He gradually lost weight, but continued working as a clerk until April, 1958. He then developed vomiting and abdominal pain with distension, and was readmitted to hospital with intestinal obstruction. He died without surgical intervention.

Necropsy (Dr. R. L. Bishton). The abdominal cavity contained many adhesions which were most dense between the diaphragm and the right lobe of the liver, in the right renal angle, and in the pelvis, but not pronounced near the laparotomy scar. Intestinal obstruction was due to diffuse adhesions around the terminal ileum. In the mucosa of the ileum, $2 \mathrm{~cm}$. above the ileo-cæcal valve, was a small nodular tumour $6 \mathrm{~mm}$. in diameter; there was no angulation of the gut at this point. No other tumours were found. The liver $(2100 \mathrm{~g}$.) showed signs of chronic venous congestion and contained several firm pink spherical tumour deposits, up to $5 \mathrm{~cm}$. in diameter. The kidneys were normal. The pleural cavities contained a clear effusion of $200 \mathrm{ml}$. on each side. The lungs showed moderate congestion only.

The heart weighed $490 \mathrm{~g}$. The pericardial surface was roughened over the right atrium and there was a pericardial effusion of about $100 \mathrm{ml}$. The left atrium and ventricle, and the mitral and aortic valves were normal. The right atrium was dilated, with an irregular patchy white deposit on its inner surface (Fig. 5), extending to the margin of the tricuspid valve (Fig. 3B), the cusps of which were thickened and wrinkled.

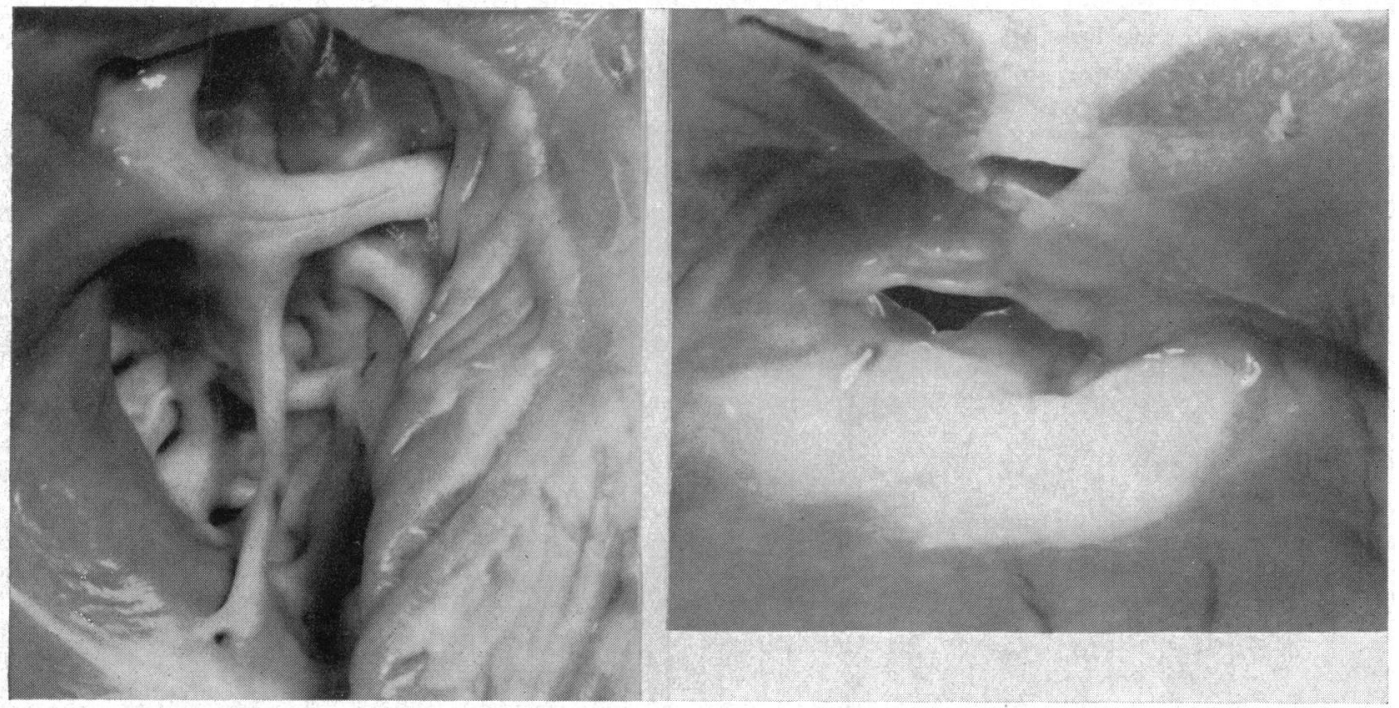

Fig. 5.-Right Atrium. The atrial appendix, showing white deposit upon the endocardium in its recesses. Case 3 .
Fig. 6.-Pulmonary Valve. The ventricular aspect of the stenosed valve, whose greatest diameter was $15 \mathrm{~mm}$. White deposit lies on the ventricular wall proximal to the valve. The cut (above) in the anterior wall of the ventricle has opened the anterior sinus from below. Case 3.

The commissures were adherent producing a moderate degree of stenosis of button-hole form. The chordæ were thickened and contracted. Functionally the valve appeared to have been both incompetent and stenotic. The right ventricle was dilated and hypertrophied, and its endocardium was free from deposit. The pulmonary valve cusps were much thickened and adherent (Fig. 6), being covered with a fibrous deposit producing a moderately severe stenosis. The pulmonary artery and its branches were normal.

Histology. The ileal tumour was a malignant carcinoid with well-marked acinar differentiation and a dense scirrhous stroma. Tumour cells had penetrated the muscularis mucosæ and were just infiltrating the inner edge of the circular muscle coat. The liver metastases had only a scanty fibrous stroma. Lung sections showed no lesions in pulmonary vessels. In the right atrium areas of deposit consisted of fibrous tissue with many fibroblasts and some mononuclear cells distributed among collagen fibres which lay parallel with the endocardial surface. The internal elastic lamina was intact, with the fibrous deposit lying upon it (Fig. 2B). There was some increase in fibrous tissue in the atrial muscle and some epicardial fibrosis. Deposits on the pulmonary and tricuspid valves resembled those in the atrium, and the collagen 
appeared to merge into the substance of the cusps. The right ventricle and the left side of the heart were normal, and the coronary arteries showed no abnormal intimal thickening.

Assay of tumour tissue by the method of Snow et al. (1955), showed a content of at least $875 \mu \mathrm{g}$ of $5 \mathrm{H}-\mathrm{T}$ per gram of metastatic tissue from the liver.

Summary. A man who died at age 36 had had facial flushings for 15 years, and a high facial colour suggesting polycythæmia for 8 years. Bowel action was always loose. For 18 months before his death he was found to have gross hepatic enlargement and the physical signs of tricuspid regurgitation. A diagnostic increase of urinary 5-H.I.A.A. was found, and laparotomy proved the presence of hepatic metastases of carcinoid tumour. He died with intestinal obstruction caused by peritoneal fibrosis. Post-mortem, characteristic lesions were seen in the right atrium and tricuspid and pulmonary valves.

\section{Electron Microscope Examination}

Fragments of the deposit were dissected free from the surface of the right atrium in each of the three cases for examination by electron microscopy by Dr. Madeline Keech. After verification by light microscopy that the specimens consisted only of the carcinoid deposit and were free of atrial wall, duplicate samples from the three cases were fragmented in water in a glass tissue grinder, and drops of the fine suspension placed on collodion-covered grids, allowed to dry, shadowed with chromium, and examined in the electron microscope (Fig. 7).

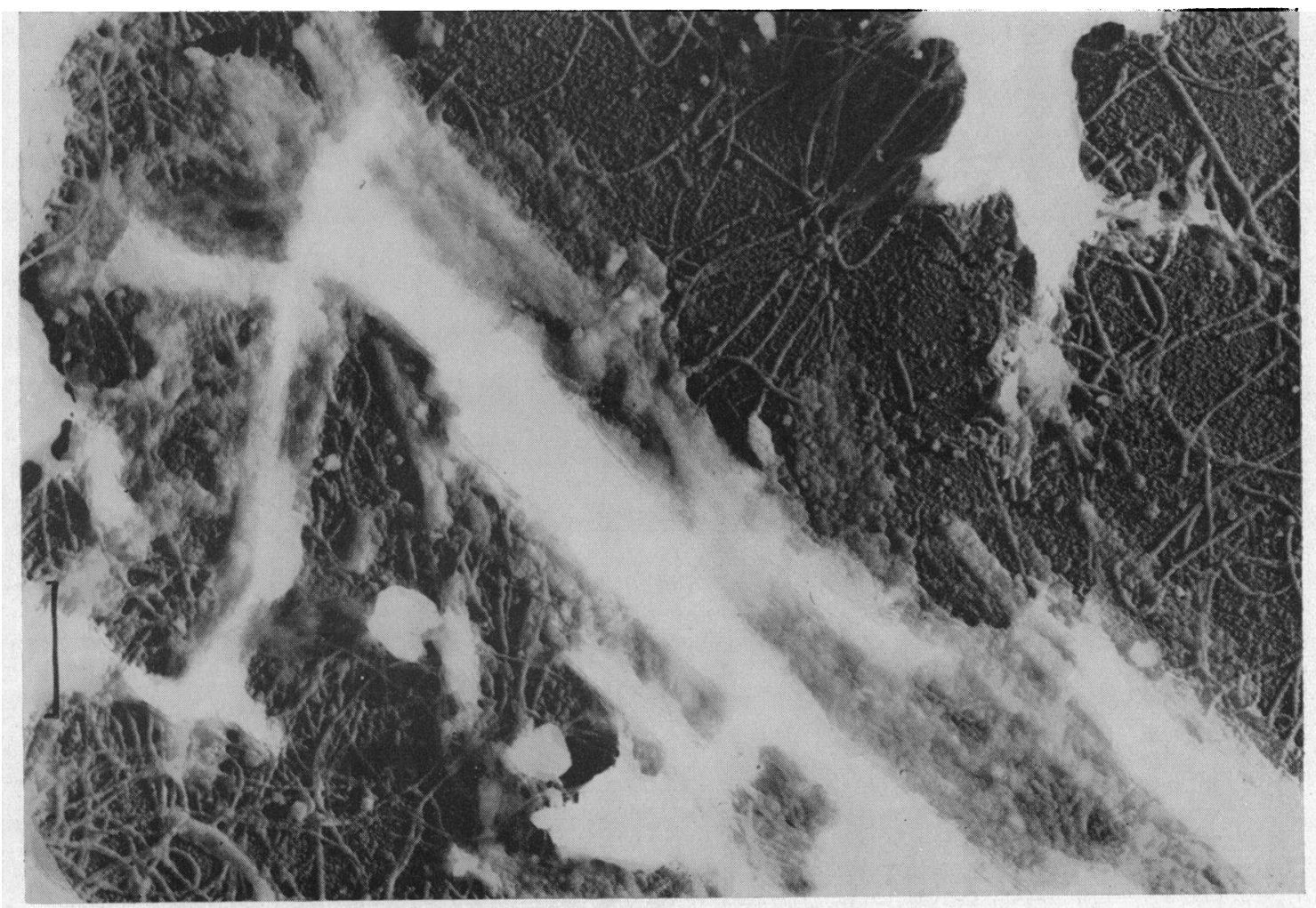

Fig. 7.-Electron Microscopy of Deposit. The scale marked on the left represents $1 \mu$; the preparation was shadowed with chromium. A representative area of the ground deposit showing (a) abundant narrow fibrils $200-500 \AA$ in width and $(b)$ portions of the thin jagged lamellæ composed of finely granular amorphous material. Some fibrils appear to be finely striated (see text). Case 2. Magnification: $\times 16,500$.

The deposits consisted of three main components: (a) abundant narrow fibrils, $200-500 \AA$ in width; (b) numerous jagged, thin, folded lamellæ of varying shape and size, composed of finely 
granular amorphous material; (c) a few dense square-ended fibres and their fragmented equivalent, namely, angular, dense bits of varying size and shape; and $(d)$ typical beaded fibrils which represent the smallest visible component of collagen (Keech, 1955). The majority of the fibrils described under (a) measured $400 \AA \AA$ in width, but occasional $500 \AA$ fibrils were seen. Some appeared to have striations at one-third of the usual spacing, whereas occasional wider ones were developing the $640 \AA$ cross-bands that characterize mature collagen. However, no typical mature collagen was seen during careful scrutiny of over 4000 microscopic fields.

Duplicate samples from Cases 2 and 3 gave identical pictures, but the scanty specimen from Case 1 contained fewer fibrils and no lamellæ.

Conclusion. These findings.are interpreted as a reticulo-collagen system indicating active formation of young collagen. The nature of the lamellæ and dense square-ended fibres are uncertain on their electron-microscope morphology alone, but in view of the histology, the lamellæ probably represent the fragmented bands of PAS-positive material, and the denser rod-shaped structures the (ground) abnormally-staining elastin fibres seen under the light microscope.

\section{Discussion}

The pharmacological action of 5 hydroxy-tryptamine $(5 \mathrm{H}-\mathrm{T})$ has been studied in detail by Erspamer (1954) and the rapidly growing work concerning it is reviewed by Page (1958). $5 \mathrm{H}-\mathrm{T}$ is formed by the argentaffin cells normally situated in the intestinal mucosa, and passes into the blood, where it is carried by the platelets, and released from them when blood clots. $5 \mathrm{H}-\mathrm{T}$ stimulates unstriped muscle to contract and in the experimental animal may cause transient rise in blood pressure apparently by local action on the blood vessel wall both in the systemic and pulmonary circulation. Muscular contraction is induced in the intestine, uterus, bladder, and bronchus. $5 \mathrm{H}-\mathrm{T}$ has a powerful antidiuretic effect probably resulting from contraction of the afferent arterioles with a reduction in the glomerular filtration rate. Its normal role in the body is still a matter for speculation.

Administration of $5 \mathrm{H}-\mathrm{T}$ in the human subject is known to cause symptoms resembling those of the carcinoid syndrome. Thus Reid (1952) noted that its intradermal or subcutaneous injection in the forearm caused a local red flare and intense venoconstriction. Page et al. (1955) showed that intravenous infusion produced pain in the vein, abdominal and bladder cramp, and tingling and burning in the face and neck. Schneckloth et al. (1957), giving $5 \mathrm{H}-\mathrm{T}$ intravenously, produced typical facial flushing in normal subjects and in two patients with carcinoid tumours. In addition one of these patients was found to flush whenever the blood pressure was made to fall by various means; a release of $5 \mathrm{H}$-T was postulated, although proof of an increase in circulating $5 \mathrm{H}-\mathrm{T}$ at the time of flushing was not obtained.

In Case 3 there was transient facial and submental œdema, followed later by polyuria. Sjoerdsma et al. (1956) reported similar œdema. Rowley and Benditt (1956) described œdema in the paws of rats after local injection of $5 \mathrm{H}-\mathrm{T}$, the mechanism apparently being exudation of fluid resulting from veno-constriction and capillary dilatation. If flushing and facial odema in our patient are attributed to a temporary increase in circulating $5 \mathrm{H}-\mathrm{T}$, subsequent polyuria may have represented the recovery phase from an antidiuresis due to $5 \mathrm{H}-\mathrm{T}$.

Slow Progress of Carcinoid Tumours. Carcinoids arising in the appendix are benign and nonmetastasizing, but those arising in other sites are malignant, though they may advance very slowly (Pearson and Fitzgerald, 1949). Both the local fibrous reaction and the nature of the distant lesions in the heart are evidence of a slowly advancing process. Although we do not know when tumour growth began in our first two cases, the long duration of symptoms in Case 3 indicates the presence of a tumour for at least 15 years. Patients with histories of over 10 years duration are cited by Mallory (1940), Waldenstrom and Ljungberg (1955), Mills (1956), and Sjoerdsma et al. (1956).

The valvular and atrial lesions in our cases were similar to those described by Macdonald and Robbins (1957). In all of them there were patchy white deposits of collagen 1-2 mm. thick on the 
atrial wall, extending on to the tricuspid valve cusps and their chordæ. The underlying endocardium was normal and its internal elastic lamina was intact, although the cusps and chordæ had been distorted by the deposit. Contraction of the chordæ and binding together of the cusps produced tricuspid valves that appeared both incompetent and stenosed; in life the physical signs were mainly those of the tricuspid stenosis in Cases 1 and 2, and of regurgitation in Case 3 . In all cases the ventricular endocardium was spared; ventricular dilatation and hypertrophy could be attributed to the valve lesions, and there was no sign of primary muscle damage. The pulmonary valve lesions resembled those of the tricuspid valves, being due to the deposit upon the cusps of collagen binding them together at the commissures to produce stenosis, and rolling them over at their free margins into the sinuses to produce regurgitation. In life the physical signs were those mainly of pulmonary regurgitation in Case 1 and stenosis in Case 2; there were no physical signs of a pulmonary valve lesion in Case 3. Beyond the pulmonary valves no lesions were found in the main pulmonary arteries, although there was intimal thickening in a few small arteries in Cases 1 and 2.

The simultaneous development of valvular stenosis and regurgitation at once suggests a resemblance to chronic rheumatic heart disease, but the resemblance is superficial. In rheumatism there are chronic inflammatory changes in the endocardium and within the cusps and chordæ, but in carcinoid disease, the deformity arises from deposit upon the endocardium, and not from change within it. In rheumatism the myocardium and pericardium are attacked but in carcinoid disease the primary change spares both. In rheumatism the valves most affected are those of the left ventricle, but in carcinoid disease lesions are confined to the valves of the right ventricle.

Two other conditions characterized by fibrosis within the heart chambers may be contrasted with carcinoid heart disease. In endomyocardial fibrosis, whether in Africans (Davies and Ball, 1955) or not (Lynch and Watt, 1957) there is diffuse fibrosis in the inner third of the ventricular wall and in the endocardium, affecting either ventricle; it is more severe towards the apex, and may extend on to the chordæ of the tricuspid valve or the posterior cusp of the mitral valve. The atria are spared. Microscopy shows loosely textured fibrous tissue within the endocardium; deep to it is a zone of vascular granulation tissue from which fibrous tissue and irregular patches of elastic tissue extend into the myocardium. In congenital fibro-elastosis the patient usually succumbs in infancy, although occasional cases may survive into adult life (Gowing, 1953; Auld and Watson, 1957). Associated malformations of the heart are common. Endocardial thickening mainly affects the left ventricle, usually over its entire wall, and the histological appearance is that of densely packed collagen and elastic fibres replacing the sub-endocardial layer, and penetrating for a variable distance into the myocardium.

The Cause of the Heart Lesions. The connection between $5 \mathrm{H}-\mathrm{T}$ and lesions in the right heart is well established. It is supported by the rare finding of additional lesser lesions in the left heart in cases with patency of the foramen ovale and a right-to-left shunt (McKusick, 1956, Case 2). Experimental attempts to produce carcinoid heart disease in animals either by intravenous infusion of $5 \mathrm{H}-\mathrm{T}$ (Correale, 1953) or by feeding the biological precursors of $5 \mathrm{H}-\mathrm{T}$ (Sjoerdsma et al., 1956) have failed, perhaps because any experiment is brief when compared with the long duration of carcinoid disease in man. The precise sites of the lesions in the right heart call for further explanation. Thus the hepatic veins, the endocardium of the right ventricle, and the walls of the main pulmonary arteries are spared, although all are exposed to circulating $5 \mathrm{H}-\mathrm{T}$. It seems that mechanical stress must be the additional factor, causing the appearance of the deposit on the tricuspid and pulmonary valve cusps and on the endothelium of the dilated right atrium. Again there is a similarity to rheumatic heart disease, in that rheumatism attacks those valves called upon to withstand the greatest pressure differences (Wood, 1954).

The mechanism by which $5 \mathrm{H}-\mathrm{T}$ causes collagen deposit is obscure. The absence of fibrin and scarcity of hæmosiderin in the deposit suggest a mode of development other than that of organization of thrombus. The possibility remains that there may be some relationship between $5 \mathrm{H}-\mathrm{T}$ and growth of fibroblasts. Thus, fibrosis in and around the primary tumour is common and there may 
be diffuse peritoneal adhesions (Cases 2 and 3); peritoneal fibrosis in our Case 2 was unusually dense but matches the descriptions given by Cassidy (1931) and by Hedinger and Gloor (1954). In our Cases 1 and 2 the primary tumour lay at a point of acute angulation caused by fibrosis in the gut wall, and in Case 1 there was dilatation of the gut above this point. Sometimes there may even be obstruction at the site of an argentaffin tumour demanding surgical relief (Duncan et al., 1955: Macfarlane et al., 1956). It would not be surprising therefore if the abdominal fibrosis and the lesions within the heart were all due to a specific action of a secretion from these tumours. This is supported by the report of Macdonald et al. (1958) that repeated subcutaneous injections of serotonin in rats produce an increase in collagen and fibroblastic proliferation at the injection site.

Treatment. Attempts at relief of symptoms by $5 \mathrm{H}-\mathrm{T}$ antagonists have so far been disappointing. Dibenylene and rauwolfia in our Case 3 brought no real relief and led to no fall in the output of urinary 5-H.I.A.A. Symptomatic remedies appear more successful, such as the use of codeine for relief of diarrhœa in our Case 1, or of chlorpromazine for relief of nausea and vomiting (Schneckloth et al., 1957). Radical relief could only be afforded by removal of tumour deposits, which can only be feasible in cases having major extra-hepatic deposits, as in the ovary or mesenteric glands.

\section{SUMMARY}

Three patients are reported who had small malignant carcinoid tumours of the ileum with large hepatic metastases and lesions of the right atrium and tricuspid and pulmonary valves.

Two died of congestive heart failure and cachexia, and one of intestinal obstruction due to adhesions. The autopsy findings are described in detail.

We wish to thank Professor T. F. Hewer for the post-mortem reports on Cases 1 and 2, Dr. R. L. Bishton for that on Case 3, and Dr. Madeline Keech for the electron-microscope studies. We are also grateful to Professor C. Bruce Perry for suggesting the diagnosis in Case 1, and to Mr. T. Schofield for performing the laparotomy in Case 3 . We are indebted to Mr. N. R. Ling for the assay of $5 \mathrm{H}-\mathrm{T}$ in tumour tissue, and to Mr. N. Swain, Mr. D. White, and Mr. G. Griffen for the photographs. We wish to thank the Colston Research Fund for a contribution towards the cost of the colour plate.

\section{REFERENCES}

Auld, W. H. R., and Watson, H. (1957). Brit. Heart J., 19, 186.

Biorck, G., Axen, O., and Thorson, A. (1952). Amer. Heart J., 44, 143.

Cassidy, M. A. (1930). Proc. Roy. Soc. Med., 24, 139. (1931). Proc. Roy. Soc. Med., 24, 920.

Correale, P. (1953). Boll. Soc. Ital. Biol. sper., 29, 1594.

Davies, J. N. P., and Ball, J. D. (1955). Brit. Heart J., 17, 337.

Duncan, D., Garven, J. D., and Gibbons, J. L. (1955). Brit. med. J., 2, 1586.

Erspamer, V. (1954). Pharm. Rev., 6, 425.

Goble, A. J., Hay, D. R., and Sandler, M. (1955). Lancet, 2, 1016.

Hudson, R., and Sandler, M. (1956). Brit. Heart J., 18, 544.

Gowing, N. F. C. (1953). J. Path. Bact., 65, 13.

Hanson, A., and Serin, F. (1955). Lancet, 2, 1359.

Hedinger, C., and Gloor, R. (1954). Schweiz. med. Woch., 84, 942.

Isler, P., and Hedinger, C. (1953). Schweiz. med. Woch., 83, 4.

Keech, M. E. (1955). Ann. rheum. Dis., 14, 19.

Lynch, J. B., and Watt, J. (1957). Brit. Heart J., 19, 173.

Macdonald, R. A., and Robbins, S. L. (1957). Arch. Path., 63, 103.

- - - and Mallory, G. K. (1958). Proc. Soc. Exp. Biol. Med., 97, 334.

Macfarlane, P.S., Dalgleish, C. E., Dutton, R. W., Lennox, B., Nyhus, L. M., and Smith, A. N. (1956). Scott. med.J., $1,148$.

McKusick, V. A. (1956). Bull. Johns Hopk. Hosp., 98, 13.

Mallory, T. B. (1940). New Eng. J. Med., 222, 684.

Mills, G. Y. (1956). Ann. intern. Med., 45, 1213.

Page, I. H. (1958). Physiol. Reviews, 38, 277.

, Corcoran, A. C., Udenfriend, S., Sjoerdsma, A., and Weissbach, H. (1955). Lancet, $1,198$.

Pearson, E. M., and Fitzgerald, P. J. (1949). Cancer, 2, 1005.

Reid, G. (1952). J. Physiol., 118, 435.

Rosenbaum, F. F., Santer, D. G., and Claudon, D. B. (1953). J. Lab. clin. Med., $42,941$.

Ross, J. (1948). Post-mortem Appearances. Oxford University Press, London, p. 288.

Rowley, D. A., and Benditt, E. P. (1956). J. exp. Med., 103, 399. 
Schneckloth, R., Page, I. H., del Greco, F., and Corcoran, A. C. (1957). Circulation, 16, 523.

Scholte, A. J. (1931). Beitr. path. Anat., 86, 440.

Sjoerdsma, A., Weissbach, H., and Udenfriend, S. (1956). Amer. J. Med., 20, 520.

Snow, P. J. D., Lennard-Jones, J. E., Curzon, G., and Stacey, R. S. (1955). Lancet, $2,1004$.

Thorson, A. Biorck, G., Bjorkman, G., and Waldenstrom, J. (1954). Amer. Heart J., 47, 795. (1958). Acta med. Scand. supp., 334.

Udenfriend, S., Weissbach, H., and Clark, C. T. (1955). J. Biol. Chem., 215, 337.

Waldenstrom, J., and Ljungberg, E. (1953). Svenska Lakartidn., 50, 690.

- (1955). Acta med. Scand., 152, 293.

Wood, P. (1954). Brit. med. J., 1, 1051, 1113. 